\title{
AC 2007-730: INNOVATIVE EXPOSURE TO ENGINEERING BASICS THROUGH MECHATRONICS SUMMER HONORS PROGRAM FOR HIGH SCHOOL STUDENTS
}

\section{John Mativo, Ohio Northern University}

JOHN MATIVO teaches Materials and Product Manufacturing courses at Ohio Northern University. He has conducted several summer projects for middle an high school students. His university teaching experience totals eleven years six of which he served as Department of Technology Chair at the University of Eastern Africa, Baraton. He holds degrees in Technology, Education and Engineering. His Doctorate is from the University of Georgia. He is a member of Sigma Xi, Epsilon Pi Tau, Phi Kappa Phi, and Phi Beta Delta.

\section{Adam Stienecker, Ohio Northern University}

ADAM STIENECKER teaches electronics and applied control systems courses at Ohio Northern University in the Department of Technological Studies. He holds undergraduate and doctorate degrees in Electrical Engineering from the University of Toledo in Ohio. His areas of research include alternative energy and alternative energy storage devices. 


\section{Innovative Exposure to Engineering Basics through Mechatronics Summer Honors Program for High School Students}

\section{Background}

The American Competitive Initiative ${ }^{1}$ set the stage for stronger educational programs through research and educational activities through the year 2016. The National Science Foundation (NSF) is leading the way in initiating interdisciplinary learning methods and in particular the Science, Technology, Engineering, and Mathematics (STEM) areas ${ }^{2}$. Examples of the NSF programs taking root in this area include the basic STEM learning strategies, the Scholarships in Science, Technology, Engineering, and Mathematics (S-STEM), and the STEM -Talent Expansion Programs (STEP). State Departments of Education are also providing grants for STEM initiatives. The Ohio Department of Education, for example, awarded several grants towards this cause recently. A Masters in Arts in STEM has been developed by the University of Massachusetts ${ }^{3}$. The intensity of activities above indicates a need to interest secondary school students with STEM curriculum. With keen interest in introducing and energizing secondary school students to STEM curriculum, the authors (we), together with local secondary school teachers, evaluated the typical high school curriculum and found that while Science, Technology, and Mathematics (STM) were widely taught, Engineering was mostly absent in the curriculum. We also noted that engineering was the subject matter that brought STM to life through application of the knowledge gained. After several discussions, the authors selected Mechatronics as an avenue for cultivating interest in STEM and maintaining it during high school and post high school years because of its dynamic nature and ability to manipulate systems. Interest is cultivated in students having an aptitude in STEM areas by introducing them to relevant tools that help to open possibilities.

\section{The Program}

The Ohio Department of Education Office for Exceptional Children offers very competitive Summer Honors Grants. The Mechatronics program was funded in 2006 as part of a University Summer Honors Institute. Students participated in a pre and post assessment to evaluate their perceived knowledge in areas covered. The one week residential Mechatronics program was selected because of its nature of integrating mechanical, electrical, controls, and programming. We made assumptions that students attending the program had some degree of knowledge and skills in science, math, and technology acquired from their secondary education that would enable them to grasp the mechatronics subject matter and spend more time on application.

The one week course curriculum was presented through mini-lessons, demonstrations, and class projects before embarking on team projects that drove the applied learning. Subject matter covered in the program included:

- Engineering Design

- Mechanical systems

- Electronic Systems and Programming

- Product Design

- Team work basics 
Welcoming events took place the first evening. Students were then briefed about the events for the week and they seemed excited. Eleven students had registered for the program, although it was initially planned for eight. As a first activity of the students, a pre-assessment exercise was administered. After which, students were introduced to their curriculum that would include the aforementioned activities.

Engineering Design - The basics of engineering design included: understanding the problem, generating concepts, iteration for optimization, and testing the product. Our presentation on engineering design was spread throughout the week as different parts were addressed at relevant times.

We decided to introduce students to data acquisition methodology and materials behavior. Introducing students to a data collection method through testing would provide students the knowledge of how empirical values are gathered and placed in documents for use. This activity would cause students to gain a level of comfort in using empirical data documented in various handbooks. Material behavior is critical to any engineering design because it provides the basis of material selection that will provide the performance needed to make a product safe and functional repeatedly. The Universal Testing machine was selected because of ease of use and readily available materials that could be made into specimens. Aluminum specimens of $1 / 4$ " x 1 " x 12" were cut off from a ASTM-B-221 Kaiser 6061-T6511 stock. These specimens were then placed carefully in the Tinus Olsen 60,000 Lb Universal Testing Machine (UTM) grippers for tensile testing as shown in figures 1 and 2 . A load was placed on the specimen until ultimate stress as shown in figure 3 . Table 1 shows results from student laboratory exercises and calculation of relevant data.
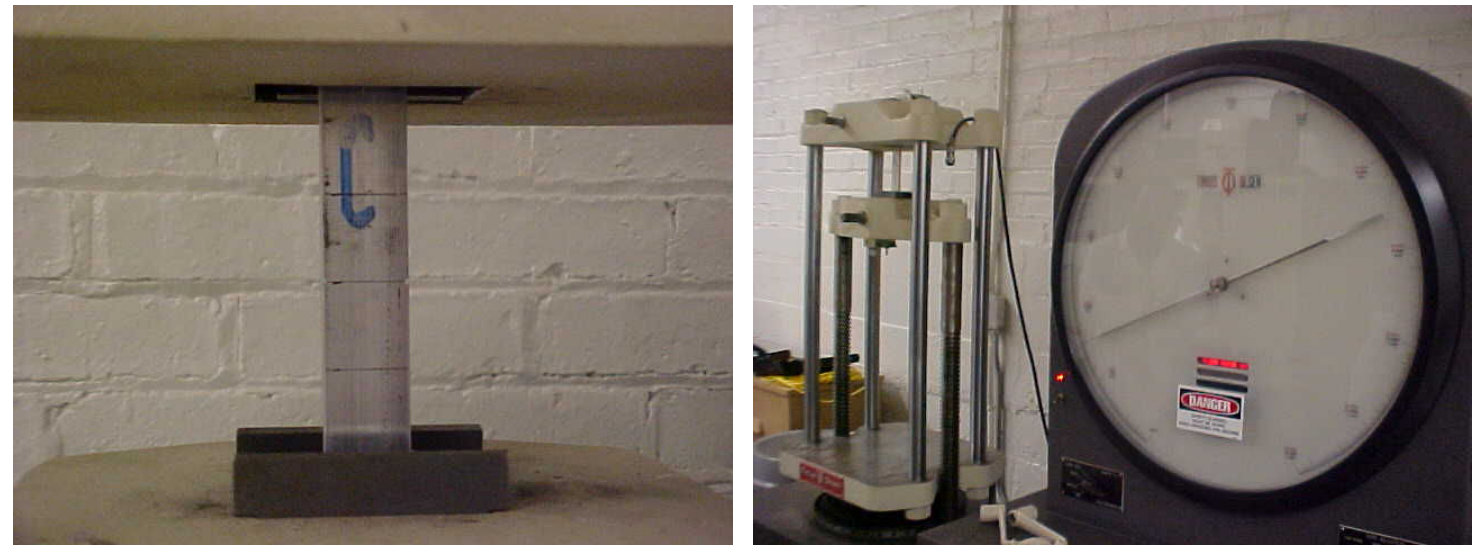

Figure 1: Specimen placed in UTM

Figure 2: Specimen under load 


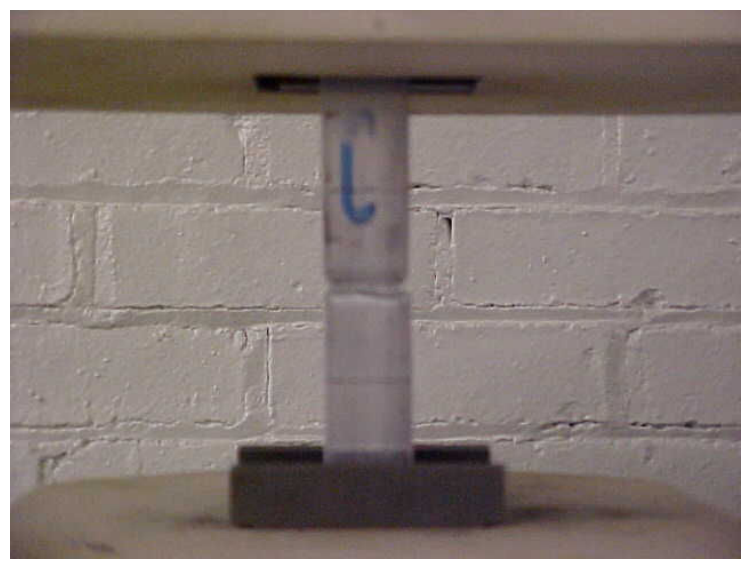

Figure 3: Specimen near fracture

Table 1: Data collected from this experiment and relevant calculated values

\begin{tabular}{|l|l|l|l|l|l|l|l|}
\hline Specimen & $\begin{array}{l}\text { Length } \\
\text { Original } \\
\text { (in) }\end{array}$ & $\begin{array}{l}\text { Length } \\
\text { Final } \\
\text { (in) }\end{array}$ & $\begin{array}{l}\text { Strain } \\
\text { (in/in) }\end{array}$ & $\begin{array}{l}\text { Cross- } \\
\text { section } \\
\text { Area }\left(\mathrm{in}^{2}\right)\end{array}$ & $\begin{array}{l}\text { Applied } \\
\text { Force (lb) }\end{array}$ & $\begin{array}{l}\text { Stress } \\
(\mathrm{psi})\end{array}$ & $\begin{array}{l}\mathrm{E} \\
\left(\mathrm{x} 10^{6}\right) \\
(\mathrm{psi})\end{array}$ \\
\hline $\mathrm{A}$ & 12 & 12.05 & .0042 & .25 & 11,500 & 46,000 & 11.040 \\
\hline $\mathrm{B}$ & 12 & 12.06 & .0050 & .25 & 10,700 & 42,800 & 8.560 \\
\hline $\mathrm{C}$ & 12 & 12.06 & .0050 & .25 & 11,300 & 45,200 & 9.040 \\
\hline $\mathrm{D}$ & 12 & 12.06 & .0044 & .25 & 11,400 & 45,600 & 10.364 \\
\hline
\end{tabular}

Engineers Edge ${ }^{4}$ data shows Aluminum's alloy Modulus of Elasticity to be $10.2 \times 10^{6}$ psi while Matweb $^{5}$ - Material Property Data placed the Aluminums' 6061T-651value to be $10 \times 10^{6}$ psi. The experiments' average value was $9.751 \times 10^{6}$ psi.

Strain was computed using the equation 1.

strain $=\frac{\text { change in length }}{\text { original length }}=\varepsilon\left(\frac{\text { in }}{\text { in }}\right)$

eq. 1

Stress was computed using the equation 2,

$\sigma=\frac{F}{A}$

eq. 2

where $\mathrm{F}$ is the applied force and $\mathrm{A}$ is the cross sectional area. The Modulus of elasticity was computed using equation 3 ,

$E=\frac{\sigma}{\varepsilon}$

eq. 3

where $\sigma$ is the stress and $\varepsilon$ is the strain. 
We advised students to use reputable handbooks for reference in the event they needed to search for material data.

Mechanical Systems - Presentations on mechanical advantage used for various applications were explored. The purpose of the exercise was to introduce students on how to create dynamic products by taking advantage of this phenomenon. Mechanical settings such as gears, pulleys, pneumatic, and hydraulic systems were presented. Students were asked to consider what power transmission would be best suited for a given situation. This topic was purposely selected to provide participants with an awareness of possible methods to maximize power transmission within drive trains. Using their background in mathematics and science, students were able to compute and make intelligent choices of scenarios that would provide an optimal mechanical advantage. An example, for instance, was to determine how the two gear system in figure 4 would function as a speed increasing system and when it would function as speed reducing system. In addition to the function, what would be the mechanical advantage or disadvantage realized from each function depicted above?

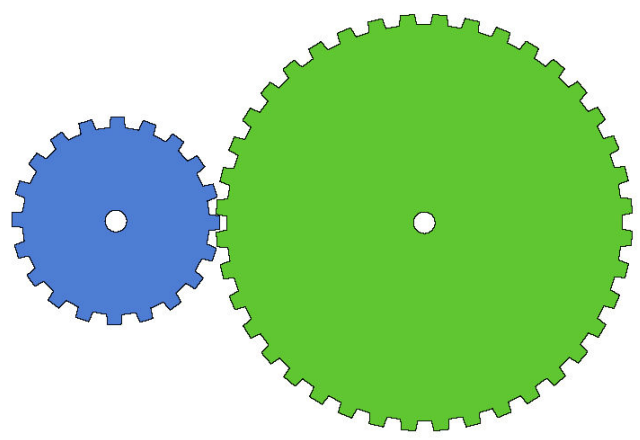

Figure 4: Sample Mechanical System

By responding to the question above, it was expected that students would count the number of teeth in each gear prior to engaging in exact computation.

The uses of mechanism to perform certain functions intermittently or continuously were discussed. Examples such as windshield wiper systems, and robotic axis movements were demonstrated. Students were then introduced to Corel Draw, where they could design their mechanical aspects of the project such as the platform which would hold their robot parts, the wheels or any other part. The design would be sent to the Universal Laser Systems machine that would cut or engraver. Students learned how to set and operate the machine as they made their parts. Wood and acrylic sheets were the materials availed to students for this purpose.

Electronic Systems and Programming - As in all mechatronic systems, electronics and programming were involved in the projects that the students completed. Therefore, before they were capable of designing a system involving electronics they were required to understand the tools which were at their disposal. These electronic "tools" were as follows:

- Basic Stamp 2 Microcontroller

- LM317 Variable Linear Voltage Regulator

- GP2D02 Infrared Distance Sensor 
- Futaba S148 continuous rotation servo motor

When faced with a design problem of a complex system young students rarely realize that a complex system is made up of many simpler systems or circuits. Therefore, to advance them to a point where they felt comfortable designing their system we took them through the design of a similar system one building block at a time. The first and central block was the microcontroller.

The Basic Stamp 2 Microcontroller (BS2) - To introduce them to the microcontroller they were given a simple exercise which required them to plug in the BS2 and connect it to power and a single LED. Once properly connected, the exercise detailed a step-bystep process to correctly setup the software to communicate to the BS2. Then they were given a simple, 6 line program that simply blinked an LED. Then they were asked to start changing a few numbers in the program to determine what happened. In that, discovery took place. Instead of teaching them what each command did, they were able to deduce the function of each command and therein learning took place. Finally, they were given a more complicated program and the BS2 manual. This program included variables, IF statements, and the DEBUG command along with those previously discovered in the first program. Already very hungry to harness the full functionality of the microcontroller, it did not take them long to start manipulating and changing the more complicated program to their liking.

The LM317 Variable Voltage Regulator - Since the BS2 is powered via $+5 \mathrm{~V}$ and they had $9 \mathrm{~V}$ batteries at their disposal the voltage needed to be regulated down to $+5 \mathrm{~V}$. The LM7805 would be a sufficient choice but it creates a very simple circuit and part of these exercises was to build knowledge. Therefore, a somewhat more complicated choice was made to use the LM317 which requires two external resistors to accomplish the task of $+5 \mathrm{~V}$ regulation. Students were instructed to simply connect the $9 \mathrm{~V}$ battery to the regulator and measure the output. This investigation of the building block by itself leads to confidence that the unit is doing what it claims. Once the regulator was functioning the students ran their BS2 from the 9V battery through the LM317.

GP2D02 Infrared Distance Sensor - Now that the students had a functioning and portable microcontroller it was time to discuss inputs and outputs. We began with the infrared distance sensor. The approach was the same. We gave them a simple wiring diagram and a sample program and they were off. Once again it was the student's task to figure out what each portion of the code was doing by reading instructions and changing values. No lecture or explanation was given other than the sample code being commented as it would normally be.

Once the next building block was functioning, the student then determined what the value of the sensor variable was (0-255) given certain distances away and constructed a simple chart so that the algorithm development would be simplified. Now the student was instructed to create a very simple program that turned on an LED if the sensor sensed something 10 inches away or closer. 
Futaba S148 continuous rotation servo motor - Once again, the students were given a simple wiring diagram and a sample program. However, this time the sample program had no comments. It was the student's task to write the comments in based on their research through the BS2 manual. As they discovered the purpose of each line they became more and more anxious to get to the project at hand, but one more step was required. The students then constructed a simple program to turn the motor when the sensor read a value indicating less than 10 inches and stopped the motor when no object was sensed within the 10 inches.

It is important to note that the students did not understand everything about what they were doing. The students had no idea what the Zener diode was for in between the sensor and the BS2 connection. They had no idea how the voltage regulator functioned, nor did they know what a byte or a bit was. The fact of the matter is that they didn't need to know this information to make something work. They only needed the critical details at this level. Of course, further down the road they will discover what that Zener diode was for and what a byte is, but that is only required after they've made that decision to go the direction of engineering in their college careers. Presenting only the critical information to get excitement is the key to interesting many students in engineering.

Product Design - The knowledge and skills of STEM courses are mostly used to develop products. The authors made a deliberate decision to incorporate a visit to Center of Science and Industry (COSI) in Columbus Ohio to expose students to design progression of products from different time eras. Both the field trip and classroom activity revealed that a product has to provide the expected function adequately, must be safe to operate, and also provide emotional appeal. A simple example of a lunch box was one of illustrations demonstrated to drive the point home. A lunch box that functions adequately and is safe is sufficient for a parent or guardian to place food for their child. However, with no child appeal, such as favorite characters on the lunchbox cover, a child was unlikely to choose it for a lunch box. Students were therefore challenged to keep in mind these three aspects when developing their autonomous robots. The production and electronic laboratories were made available for the students to use. All tools in those labs were accessible to them for use. The tools that were mostly used included the Universal Laser System Machine (ULSM), table saw, band saw, radial arm saw, glue gun, computers with Labview applications, Corel Draw, and soldering gun. 
As seen in figures 5 through 9, each team was creative and worked to make their product functional, safe, and appealing.

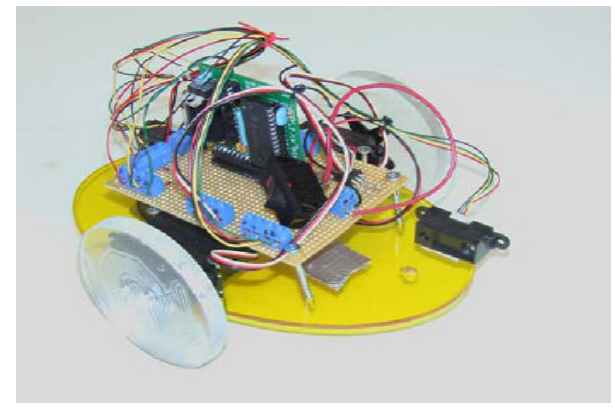

Figure 5: Team \#1 - design included an oval platform and round plastic wheel designed and cut using the ULSM.

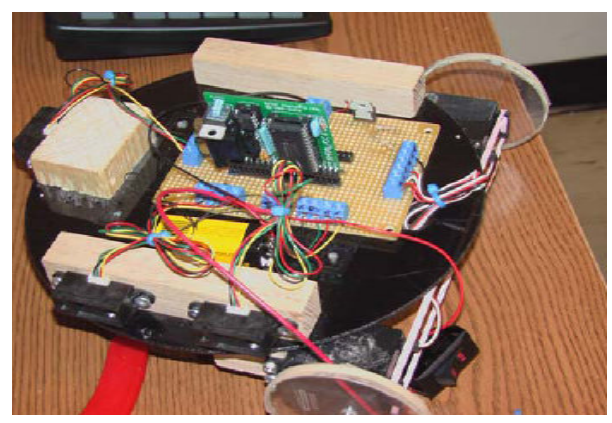

Figure 6: Team \#2 - round platform and wheels cut using the laser engraver and cutter. Wood is used wood to place the sensors.

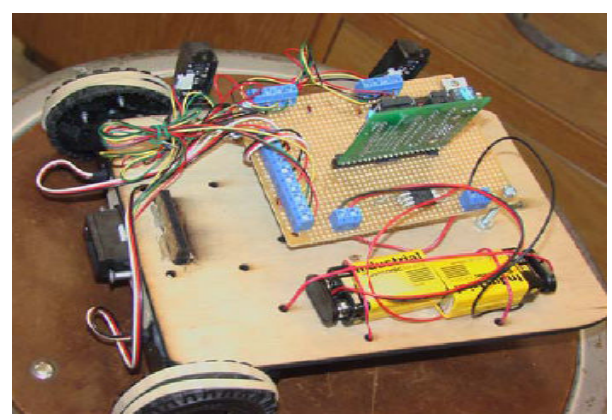

Figure 7: Team \#3 - used a plywood platform and off the shelf wheels with a swivel ball for the front rotation. 


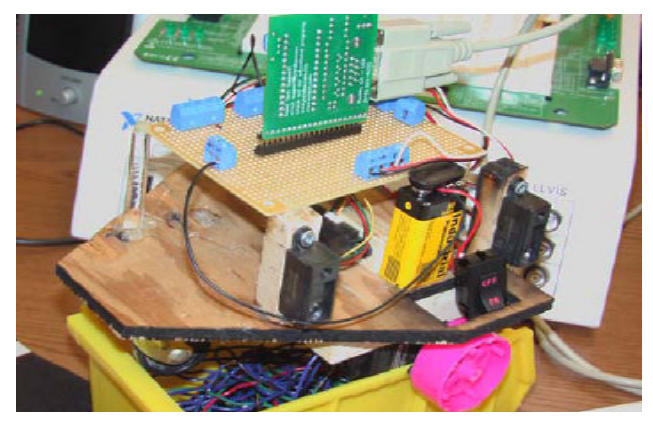

Figure 8: Team \#4 - used plywood platform and off the shelf plastic wheels with a swivel wheel in the front.

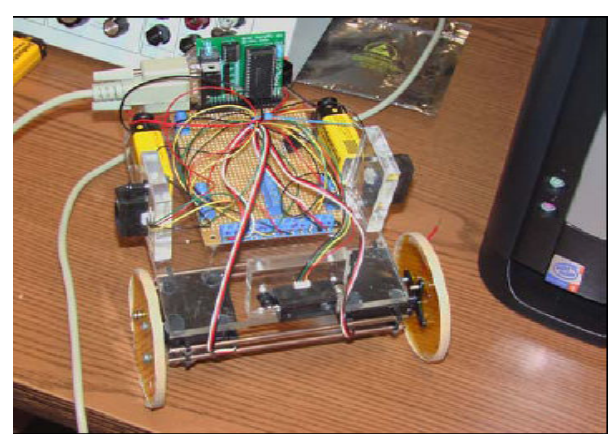

Figure 9: Team \#5 - used acrylic for their rectangular platform and wheels cut using the ULSM.

From their learning, students realized that they had to break their projects into subproblems. They used basic physics such as gravity and center of mass to balance their robots, programmed to optimize behavior of their robots, and troubleshot each independent function to ensure accurate performance. Through this activity, they had been introduced to the use of the five technical assumptions to problem solving in engineering.

Teamwork Basics - Common vision, cooperation, and synergy were encouraged throughout the project. Students knew that they had to participate in a team environment to be able to succeed in their efforts. Four of the teams worked exceedingly well together. One team, however, had a problem. One of the team members wanted to lead in every way and at the end the team member gave up because his ideas were not functioning. The two other members stepped in and salvaged their project by bringing in their ideas and working tirelessly to beat the deadline while the other team member slept.

\section{Results \& Conclusions}

Overall, the Mechatronics program for learning basics in engineering worked very well by introducing participants to data collection and use, brainstorming, systematic prediction and iteration to perform controls, and design and building of mechanical parts. Results from the students shown in figure 10 indicate that there was significant increase 


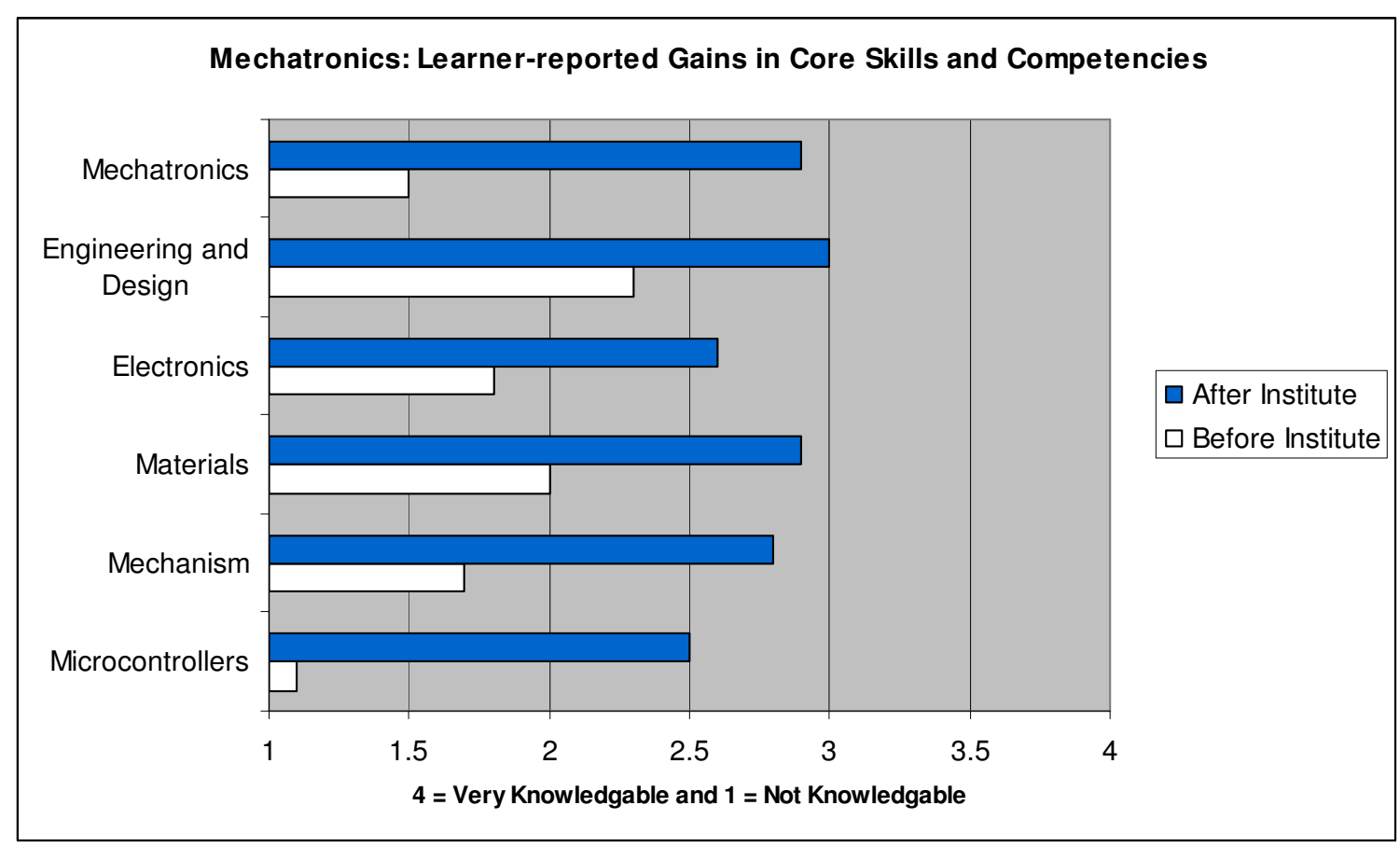

Figure 10: Pre and post assessment results.

in knowledge. This increase in knowledge implies an inherent increase in interest in the subject matter. The characteristics of students that participate in this program were similar in that they had an aptitude for STEM areas. However, they were limited in their associating learned subject matter to further discovery and knowledge. In this program they were able to use their knowledge in math and science to engineer a product through the use of technology that they had previously lacked. Four robots were able to complete the maze within three minutes while one robot was not able to move from the start line. Each team received a prize corresponding to their performance. Students cultivated interest as evidenced by their wishes to take their projects home to further improve them. We noted the time limitations in developing such curriculum and we recommend a two week camp for such activities to further aid in the cultivation of interest in STEM areas. 


\section{References}

[1] Bush, George. (2006). American Competitive Initiative: Leading the World in Innovation. The White House. Washington DC. http://www.whitehouse.gov/stateoftheunion/2006/aci/aci06booklet.pdf

[2] Olsen, K.L. (2006). Living "Smart" in a World with Technology. International Technology Educators Association Annual Conference, March 23. Baltimore, MD. http://www.nsf.gov/news/speeches/olsen/06/ko060323_iteaconf.jsp

[3] University of Massachusetts (2007). www.massachusetts.edu/stem/index.html

[4] Engineers Edge (2007).

http://www.engineersedge.com/manufacturing_spec/average_properties_structural_materials.htm

[5] Matweb (2007). http://www.matweb.com/search/GetProperty.asp 